\title{
Perioperative outcomes of interrupted anticoagulation in patients with non-valvular atrial fibrillation undergoing non-cardiac surgery
}

\author{
Bo Eun Park, Myung Hwan Bae, Hyeon Jeong Kim, Yoon Jung Park, Hong Nyun Kim, Se Yong Jang, \\ Jang Hoon Lee, Dong Heon Yang, Hun Sik Park, Yongkeun Cho, Shung Chull Chae
}

Department of Internal Medicine, Kyungpook National University Hospital, School of Medicine, Kyungpook National University, Daegu, Korea

Received: May 15, 2020

Revised: June 9, 2020

Accepted: June 17, 2020

Corresponding author:

Myung Hwan Bae

Division of Cardiology, Department

of Internal Medicine, Kyungpook

National University Hospital, School

of Medicine, Kyungpook National

University, 130 Dongdeok-ro, Jung-

gu, Daegu 41944, Korea

Tel: +82-53-200-5525

Fax: +82-53-426-2959

E-mail:bmh0325@knu.ac.kr
Background: This study aimed to investigate the incidences of and risk factors for perioperative events following anticoagulant discontinuation in patients with non-valvular atrial fibrillation (NVAF) undergoing non-cardiac surgery.

Methods: A total of 216 consecutive patients who underwent cardiac consultation for suspending perioperative anticoagulants were enrolled. A perioperative event was defined as a composite of thromboembolism and major bleeding.

Results: The mean anticoagulant discontinuation duration was $5.7( \pm 4.2)$ days and was significantly longer in the warfarin group $(p<0.001)$. Four perioperative thromboembolic $(1.9 \%$; three strokes and one systemic embolization) and three major bleeding events (1.4\%) were observed. The high $\mathrm{CHA}_{2} \mathrm{DS}_{2}-\mathrm{VASC}$ and HAS-BLED scores and a prolonged preoperative anticoagulant discontinuation duration $(4.4 \pm 2.1$ vs. $2.9 \pm 1.8$ days; $p=0.028)$ were associated with perioperative events, whereas the anticoagulant type (non-vitamin $\mathrm{K}$ antagonist oral anticoagulants or warfarin) was not. The best cut-off levels of the HAS-BLED and $\mathrm{CHA}_{2} \mathrm{DS}_{2}$-VASc scores were 3.5 and 2.5, respectively, and the preoperative anticoagulant discontinuation duration for predicting perioperative events was 2.5 days. Significant differences in the perioperative event rates were observed among the four risk groups categorized according to the sum of these values: risk $0,0 \%$; risk 1 , $0 \%$; risk 2, 5.9\%; and risk 3, 50.0\% ( $p<0.001)$. Multivariate logistic regression analysis showed that the HAS-BLED score was an independent predictor for perioperative events.

Conclusion: Thromboembolic events and major bleeding are not uncommon during perioperative anticoagulant discontinuation in patients with NVAF, and interrupted anticoagulation strategies are needed to minimize these.

Keywords: Anticoagulants; Atrial fibrillation; Perioperative period; Surgery; Thromboembolism

\section{Introduction}

Atrial fibrillation $(\mathrm{AF})$ increases the morbidity and mortality risks in affected patients and is closely related to stroke incidence [1-5]. Anticoagulation is important to reduce these risks. Warfarin has been used for preventing stroke for many decades; recently, non-vi- tamin Kantagonist oral anticoagulants (NOACs) have been developed and used for this purpose [6-11]. If patients with $\mathrm{AF}$ who are undergoing anticoagulant therapy need surgery, anticoagulant discontinuation is required for certain duration owing to concerns regarding the increased risk of intraoperative bleeding [6-9]. However, anticoagulant discontinuation can increase the risk of periopera-

Copyright (C) 2020 Yeungnam University College of Medicine

This is an Open Access article distributed under the terms of the Creative Commons Attribution Non-Commercial License (http://creativecommons.org/licenses/by-nc/4.0/) which permits unrestricted non-commercial use, distribution, and reproduction in any medium, provided the original work is properly cited. 
tive stroke; thus, it is necessary to determine the appropriate anticoagulant discontinuation duration to minimize the risk of perioperative stroke and bleeding. Current guidelines on anticoagulant use in patients with AF have suggested the perioperative anticoagulant discontinuation duration according to the bleeding risk associated with the surgery; conversely, they take into account the pharmacokinetic characteristics of anticoagulants and do not reflect the results of clinical studies [7,10-12]. Consequently, in this study, we investigated the incidences of and risk factors for thromboembolism and major bleeding following perioperative anticoagulant discontinuation in patients with non-valvular AF (NVAF) undergoing non-cardiac surgery.

\section{Materials and methods}

The study was approved by the by the Institutional Review Board (IRB) of the Kyungpook National University Hospital (IRB No: 2019-11-040). Informed consent was waived by the board.

This observational study included 216 consecutive patients with NVAF who consulted the Department of Cardiology for suspending their perioperative anticoagulant use at the Kyungpook National University Hospital between March 2015 and September 2019. Patients with a mechanical prosthetic heart valve or moderate to severe mitral valve stenosis, as well as those with newly diagnosed AF or those who did not take anticoagulants (NOACs or warfarin), were excluded. All surgeries/interventions were categorized into three groups depending on the surgical bleeding risks according to the 2018 European Heart Rhythm Association Practical Guidelines on the NOACs use in patients with AF [11]: those not necessarily requiring discontinuation (dental intervention, ophthalmology, endoscopy/cystoscopy without biopsy, and superficial surgery), those with a low bleeding risk (endoscopy/cystoscopy with biopsy, prostate or bladder biopsy, and angiography), and those with a high bleeding risk (thoracic, abdominal, orthopedic, spinal, and vascular surgeries, complex endoscopic procedures, and extracorporeal shock wave lithotripsy).

The demographic and clinical characteristics of the patients were examined, including age, sex, body weight, pre-medication, laboratory findings, and cardiovascular risk factors (hypertension, diabetes mellitus, previous history of myocardial infarction, stroke/transient ischemic attack [TIA], congestive heart failure, vascular disease, and chronic kidney disease). The $\mathrm{CHA}_{2} \mathrm{DS}_{2}$ VASc and HAS-BLED scores were used to assess the stroke and bleeding risks. The left atrial anteroposterior diameter $(\mathrm{mm})$ and left ventricular ejection fraction (LVEF, \%) were measured using two-dimensional echocardiography. Regarding laboratory data, the creatinine levels and international normalized ratio values were obtained on the date closest to the actual surgery date. Furthermore, information on pre-hospital medication including warfarin, NOACs (apixaban, dabigatran, edoxaban, and rivaroxaban), and concomitant antiplatelet agents was collected. The anticoagulant discontinuation duration was measured by taking into consideration the actual time the drug was last taken. Heparin bridging therapy used a twice-daily low molecular weight heparin and was discontinued 24 hours before the planned surgery or procedure.

A perioperative event was defined as a composite of stroke, systemic embolism, and major bleeding owing to anticoagulant discontinuation of up to 30 days postoperatively. Stroke was defined as a sudden focal neurological deficit consistent with the territory of a cerebral artery occlusion documented by a brain imaging study. Moreover, systemic embolism was defined as a sudden vascular occlusion in an organ or extremity. Major bleeding was defined as clinically overt bleeding with a decrease of at least $2 \mathrm{~g} / \mathrm{dL}$ in hemoglobin levels or transfusion of at least two units of packed red blood cells or that resulting in death.

Data are expressed as mean \pm standard deviation and percentages for continuous and categorical variables, respectively. All comparisons between the baseline variables were performed using the Student t-test and chi-square test for continuous and categorical variables, respectively. All $p$-values were two-sided, and $p<0.05$ was considered significant. Multivariate logistic regression analysis was used for identifying independent predictors of a perioperative event. The receiver operating characteristics (ROC) curve analysis was performed to determine the cut-off values for predicting a perioperative event. All statistical analyses were performed using the IBM SPSS version 20.0 (IBM Corp., Armonk, NY, USA).

\section{Results}

All surgery types $(n=216)$ were classified into the following three groups according to the risk of bleeding; those not necessarily requiring discontinuation $(n=44)$, those with a low bleeding risk $(\mathrm{n}=3)$, and those with a high bleeding risk $(\mathrm{n}=169)$ (Table 1). Major orthopedic surgery was the most common type $(n=57)$, followed by abdominal $(n=45)$, spinal $(n=21)$, ophthalmological $(\mathrm{n}=18)$, and vascular $(\mathrm{n}=12)$ surgeries.

The baseline characteristics of the 216 patients (mean age, $73 \pm 8$ years; 127 males [58.8\%]) are shown in Table 2 . Hypertension (58.8\%) and diabetes mellitus (30.6\%) were common comorbidities, and 46 patients $(21.3 \%)$ had previously experienced a stroke/TIA. The mean LVEF was $55 \% \pm 9 \%$, and the mean left atrial anteroposterior diameter was $48 \pm 8 \mathrm{~mm}$. Regarding the laboratory findings, the mean estimated glomerular filtration rate was $78 \pm 33 \mathrm{~mL} / \mathrm{min}$; furthermore, 52 patients $(24.1 \%)$ had a history 
Table 1. Surgery type according to the bleeding risk $(n=216)$

\begin{tabular}{lc}
\hline Variable & Number \\
\hline Not necessarily requiring discontinuation & 44 \\
Dental interventions & 4 \\
Cartaract operation & 18 \\
Endoscopy/cystoscopy & 11 \\
Superficial surgery & 11 \\
Low bleeding risk & 3 \\
Endoscopy/cystoscopy with biopsy & 1 \\
Prostate or bladder biopsy & 1 \\
Digital subtraction angiography & 1 \\
High bleeding risk & 169 \\
Thoracic surgery & 4 \\
Abdominal surgery & 45 \\
Major orthopedic surgery & 57 \\
Spinal surgery & 21 \\
Transurethral prostate/bladder resection & 6 \\
Extracorporeal shock wave lithotripsy & 5 \\
Complex endoscopic procedure (EMR, ERCP) & 6 \\
Vascular surgery & 12 \\
Others & 13
\end{tabular}

$E M R$, endoscopic mucosal resection; $E R C P$, endoscopic retrograde cholangiopancreatography.

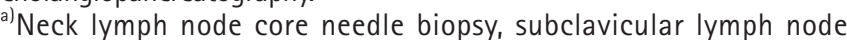
excisional biopsy, etc.

of chronic kidney disease. The mean $\mathrm{CHA}_{2} \mathrm{DS}_{2}$-VASc and HASBLED scores were $3.3 \pm 1.5$ and $1.9 \pm 1.0$, respectively.

NOACs and warfarin were prescribed for 138 and 78 patients, respectively. Rivaroxaban (41.3\%) was the most commonly prescribed NOAC, followed by apixaban (23.9\%), edoxaban (19.6\%), and dabigatran (15.2\%). The serum creatinine levels as well as male patient and heparin bridging therapy frequencies were higher in the warfarin group than in the NOACs group. However, there were no between-group differences regarding age; body weight; LVEF; left atrial size; renal function; platelet count and hemoglobin level, concomitant antiplatelet agent prescription; comorbidities such as diabetes mellitus, ischemic heart disease, stroke/TIA, heart failure, vascular disease, and chronic kidney disease; and surgery types according to the bleeding risk. Moreover, the mean $\mathrm{CHA}_{2} \mathrm{DS}_{2}$-VASc (NOACs, $3.3 \pm 1.4$ vs. warfarin, $3.1 \pm 1.8$; $p=0.410)$ and HAS-BLED ( $1.9 \pm 0.9$ vs. $2.0 \pm 1.1 ; p=0.519)$ scores were not different between the groups. The mean anticoagulant discontinuation duration was $5.7 \pm 4.2$ days, with the duration being significantly longer in the warfarin group $(8.6 \pm 4.9 \mathrm{vs}$. $4.0 \pm 2.5$ days; $p<0.001$ ) (Fig. 1 ).

Four thromboembolic events (1.9\%; three strokes and one systemic embolization) and three major bleeding events (1.4\%) occurred during the perioperative period (Table 3 ). The clinical char- acteristics of patients with perioperative stroke or major bleeding are shown in Table 4. Of them, NOACs and warfarin were prescribed in four and three patients, respectively. The $\mathrm{CHA}_{2} \mathrm{DS}_{2}-$ $\operatorname{VASc}(4.9 \pm 2.0$ vs. $3.2 \pm 1.5 ; p=0.005)$ and HAS-BLED $(3.6 \pm 1.1$ vs. $1.8 \pm 0.9 ; p<0.001)$ scores were higher and the preoperative anticoagulant discontinuation duration ( $4.4 \pm 2.1$ vs. $2.9 \pm 1.8$ days; $p=0.028$ ) was longer in patients with perioperative events than in those without them (Table 3). When all patients with low or high surgical bleeding risk were analyzed except those who did not need to stop taking anticoagulants before surgery/intervention, the $\mathrm{CHA}_{2} \mathrm{DS}_{2}$-VASc and HAS-BLED scores were higher and the duration of preoperative anticoagulant discontinuation was longer in patients with perioperative events (Table 3). Major bleeding events were significantly increased in patients treated with perioperative heparin bridging therapy ( $5.6 \%$ vs. $0 \%, p=0.015$ ). However, there was no significant difference in perioperative events according to the heparin bridging therapy status. Moreover, the anticoagulant type (NOACs or warfarin) and surgery type according to bleeding risk did not affect the perioperative event occurrence.

The area under the ROC curve for predicting the perioperative events was 0.868 ( $95 \%$ confidence interval [CI], 0.722-1.000) for the HAS-BLED score, 0.747 (95\% CI, 0.587-0.908) for the $\mathrm{CHA}_{2} \mathrm{DS}_{2}$-VASc score, and 0.733 (95\% CI, 0.508-0.958) for the preoperative anticoagulant discontinuation duration (Fig. 2). The best cut-off levels of the HAS-BLED and $\mathrm{CHA}_{2} \mathrm{DS}_{2}$-VASc scores were 3.5 and 2.5 , respectively, and the preoperative anticoagulant discontinuation duration as per the ROC curve analysis was 2.5 days. When the patients were categorized into four risk score groups according to the sum of the values defined by the cut-off levels, significant differences in the perioperative event rate were observed among the groups: risk 0 (0\%), 1 (0\%), 2 (5.9\%), and 3 $(50.0 \%)(p<0.001$; Fig. 3$)$. Multivariate logistic regression analysis showed that the HAS-BLED score (hazard ratio, 5.812; 95\% CI, 1.930-17.502) was an independent predictor for perioperative events after adjusting for the $\mathrm{CHA}_{2} \mathrm{DS}_{2}$-VASc score and preoperative anticoagulant discontinuation duration (Table 5).

\section{Discussion}

Among our study patients, thromboembolic events and major bleeding occurred in $1.9 \%$ and $1.4 \%$ of patients, respectively, who stopped anticoagulation therapy before surgery. Perioperative events are common in patients with high $\mathrm{CHA}_{2} \mathrm{DS}_{2}$-VASc and HAS-BLED scores or in those with prolonged anticoagulant discontinuation duration. However, no differences were observed in the perioperative events according to the anticoagulant (NOACs or warfarin) and surgery types. 
Table 2. Baseline clinical characteristics of the patients according to anticoagulant type

\begin{tabular}{|c|c|c|c|c|}
\hline Characteristic & All patients $(n=216)$ & NOACs $(n=138)$ & Warfarin $(n=78)$ & $p$-value \\
\hline Age (yr) & $72.9 \pm 7.7$ & $73.2 \pm 7.6$ & $72.3 \pm 8.1$ & 0.418 \\
\hline Male sex & $127(58.8)$ & $74(53.6)$ & $53(67.9)$ & 0.04 \\
\hline Body weight $(\mathrm{kg})$ & $63.0 \pm 11.5$ & $62.2 \pm 12.2$ & $64.2 \pm 10.2$ & 0.232 \\
\hline \multicolumn{5}{|l|}{ Comorbidities } \\
\hline Hypertension & $127(58.8)$ & $89(64.5)$ & $38(48.7)$ & 0.024 \\
\hline Diabetes mellitus & 66 (30.6) & $43(31.2)$ & $23(29.5)$ & 0.798 \\
\hline Ischemic heart disease & $24(11.1)$ & 15 (10.9) & $9(11.5)$ & 0.881 \\
\hline Stroke/TIA & $46(21.3)$ & $25(18.1)$ & $21(26.9)$ & 0.129 \\
\hline Congestive heart failure & $16(7.4)$ & $11(8.0)$ & $5(6.4)$ & 0.674 \\
\hline Vascular disease & $18(8.3)$ & $10(7.2)$ & $8(10.3)$ & 0.442 \\
\hline $\mathrm{CHA}_{2} \mathrm{DS}_{2}$-VASc score & $3.3 \pm 1.5$ & $3.3 \pm 1.4$ & $3.1 \pm 1.8$ & 0.41 \\
\hline HAS-BLED score & $1.9 \pm 1.0$ & $1.9 \pm 0.9$ & $2.0 \pm 1.1$ & 0.519 \\
\hline Chronic kidney disease & $52(24.1)$ & $28(20.3)$ & $24(30.8)$ & 0.084 \\
\hline \multicolumn{5}{|l|}{ Echocardiography } \\
\hline Left ventricular ejection fraction (\%) & $55.1 \pm 9.2$ & $56.0 \pm 9.2$ & $53.6 \pm 9.1$ & 0.078 \\
\hline Left atrium size, AP diameter (mm) & $47.7 \pm 7.7$ & $47.0 \pm 7.9$ & $48.9 \pm 7.8$ & 0.081 \\
\hline \multicolumn{5}{|l|}{ Laboratory findings } \\
\hline Serum creatinine $(\mathrm{mg} / \mathrm{dL})$ & $1.1 \pm 0.8$ & $0.9 \pm 0.3$ & $1.3 \pm 1.3$ & 0.008 \\
\hline $\mathrm{eGFR}(\mathrm{mL} / \mathrm{min})$ & $77.8 \pm 32.7$ & $80.0 \pm 29.1$ & $74.0 \pm 38.1$ & 0.23 \\
\hline Hemoglobin (g/dL) & $12.7 \pm 1.8$ & $12.7 \pm 1.7$ & $12.9 \pm 1.9$ & 0.412 \\
\hline Platelet $\left(\times 10^{3} / \mu \mathrm{L}\right)$ & $205.9 \pm 77.0$ & $206.5 \pm 66.1$ & $204.8 \pm 93.7$ & 0.874 \\
\hline \multicolumn{5}{|l|}{ Medication } \\
\hline Concomitant antiplatelet agents & $26(12.0)$ & $15(10.9)$ & $11(14.1)$ & 0.495 \\
\hline Heparin bridging therapy & $54(25.0)$ & $15(10.9)$ & $39(50.0)$ & $<0.001$ \\
\hline \multicolumn{5}{|l|}{ Type of NOACs } \\
\hline Apixaban & - & $33(23.9)$ & - & \\
\hline Dabigatran & - & $21(15.2)$ & - & \\
\hline Edoxaban & - & 27 (19.6) & - & \\
\hline Rivaroxaban & - & $57(41.3)$ & - & \\
\hline Surgical bleeding risk & & & & 0.395 \\
\hline Not necessarily requiring discontinuation & $44(20.4)$ & $30(21.7)$ & $14(17.9)$ & \\
\hline Low bleeding risk & $3(1.4)$ & $3(2.2)$ & 0 & \\
\hline High bleeding risk & 169 (78.2) & $105(76.1)$ & $64(82.1)$ & \\
\hline
\end{tabular}

Values are presented as mean \pm standard deviation or number (\%).

NOACs, non-vitamin K antagonist oral anticoagulants; TIA, transient ischemic attack; AP, anteroposterior; eGFR, estimated glomerular filtration rate.

Patients with $\mathrm{AF}$ are at a high risk of developing thromboembolic events and require adequate anticoagulant therapy [6-11]. However, a significant number of patients undergoing anticoagulant therapy may require surgery or other procedures, and the doctors in charge of these interventions may recommend discontinuing the anticoagulant for as long as possible due to the risk of bleeding. NOACs have shorter half-lives and achieve effective drug concentrations faster than warfarin [11-20]. Therefore, anticoagulant use guidelines for patients with AF recommend the cessation of NOACs for 48 hours in case of a high bleeding risk surgery and for 24 hours in case of a low bleeding risk surgery [11]. However, the anticoagulant discon- tinuation duration recommended by these guidelines is based on the pharmacokinetic characteristics of drugs; moreover, there have been few studies investigating the proper perioperative anticoagulant discontinuation duration [8,9,21-25].

In the warfarin era, several studies showed that perioperative warfarin discontinuation for a brief period ( $\leq 5$ days) is associated with a low risk of thromboembolism $[4,24]$. However, there are few studies examining the relationship between the anticoagulant discontinuation duration and a perioperative event in the NOACs era, except for the recent perioperative anticoagulation use for surgery evaluation (PAUSE) study [26]. 


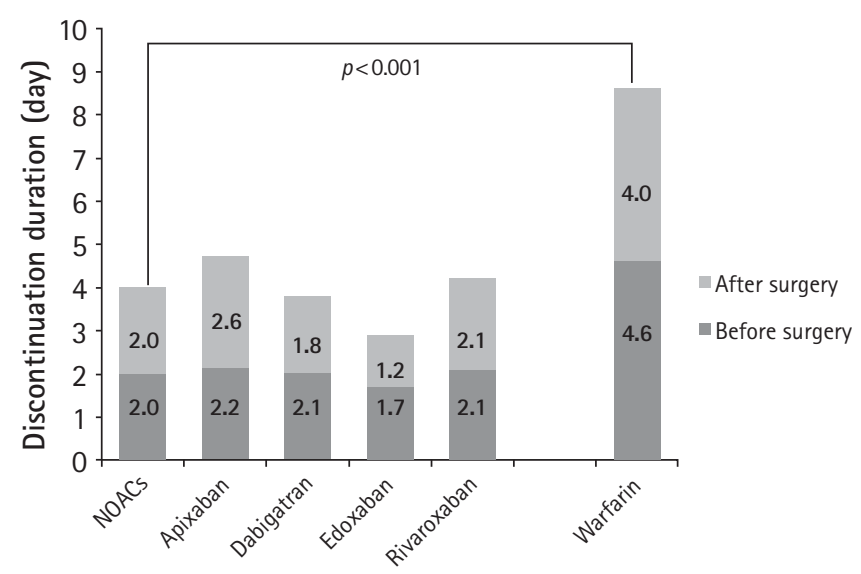

Fig. 1. Duration of perioperative anticoagulant discontinuation according to anticoagulant type (non-vitamin $\mathrm{K}$ antagonist oral anticoagulants [NOACs] vs. warfarin).
In our study, the mean preoperative anticoagulant discontinuation duration was 2 days for NOACs and 4.6 days for warfarin, which is not significantly different from the duration recommended in the guidelines [11]. Nevertheless, a perioperative event occurred in $3.2 \%$ of patients. In particular, long preoperative anticoagulant discontinuation duration was associated with perioperative events, and the thromboembolism frequency in our study (1.9\%) was relatively higher than that of the PAUSE study $(0.33 \%)$ [26]. Unlike the study environment in which the anticoagulant discontinuation duration is strictly controlled, it is believed that this difference may occur because the actual anticoagulant discontinuation duration is often different from the recommended period, at the discretion of the attending physician in real practice. It is sometimes impossible to use anticoagulants after surgery due to exces-

Table 3. Clinical characteristics of the patients according to the presence or absence of thromboembolism and/or bleeding

\begin{tabular}{|c|c|c|c|c|c|c|}
\hline \multirow{2}{*}{ Characteristic } & \multicolumn{3}{|c|}{ All patients $(n=216)$} & \multicolumn{3}{|c|}{ Low/high bleeding risk patients $(n=172)$} \\
\hline & Events $(+)(n=7)$ & Events $(-)(n=209)$ & $p$-value & Events $(+)(n=6)$ & Events $(-)(n=166)$ & $p$-value \\
\hline Age (yr) & $74.4 \pm 5.4$ & $72.8 \pm 7.8$ & 0.585 & $74.3 \pm 6.0$ & $72.6 \pm 7.8$ & 0.582 \\
\hline Male sex & $4(57.1)$ & $123(58.9)$ & 1.000 & $3(50.0)$ & $96(57.8)$ & 0.700 \\
\hline Body weight $(\mathrm{kg})$ & $65.0 \pm 10.3$ & $62.9 \pm 11.6$ & 0.633 & $65.3 \pm 11.2$ & $63.2 \pm 11.2$ & 0.642 \\
\hline \multicolumn{7}{|l|}{ Comorbidities } \\
\hline Hypertension & $7(100)$ & $120(57.4)$ & 0.043 & $6(100)$ & $99(59.6)$ & 0.083 \\
\hline Diabetes mellitus & $3(42.9)$ & $63(30.1)$ & 0.439 & $3(50.0)$ & $53(31.9)$ & 0.392 \\
\hline Ischemic heart disease & $1(14.3)$ & $23(11.0)$ & 0.567 & $1(16.7)$ & $16(9.6)$ & 0.470 \\
\hline Stroke/TIA & $3(42.9)$ & $43(20.6)$ & 0.168 & $3(50.0)$ & $36(21.7)$ & 0.131 \\
\hline Congestive heart failure & $2(28.6)$ & $14(6.7)$ & 0.087 & $2(33.3)$ & $8(4.8)$ & 0.040 \\
\hline Vascular disease & $2(28.6)$ & $16(7.7)$ & 0.107 & $1(16.7)$ & $12(7.2)$ & 0.380 \\
\hline $\mathrm{CHA}_{2} \mathrm{DS}_{2}$-VASc score & $4.9 \pm 2.0$ & $3.2 \pm 1.5$ & 0.005 & $5.0 \pm 2.1$ & $3.3 \pm 1.5$ & 0.007 \\
\hline HAS-BLED score & $3.6 \pm 1.1$ & $1.8 \pm 0.9$ & $<0.001$ & $3.8 \pm 1.0$ & $1.9 \pm 0.9$ & $<0.001$ \\
\hline Chronic kidney disease & $3(42.9)$ & $49(23.4)$ & 0.363 & $2(33.3)$ & $39(23.5)$ & 0.629 \\
\hline \multicolumn{7}{|l|}{ Echocardiography } \\
\hline Left ventricular ejection fraction (\%) & $52.9 \pm 12.8$ & $55.2 \pm 9.1$ & 0.509 & $52.2 \pm 13.9$ & $55.9 \pm 8.5$ & 0.303 \\
\hline Left atrium size, AP diameter (mm) & $46.6 \pm 7.7$ & $47.7 \pm 7.7$ & 0.708 & $4.8 \pm 0.8$ & $4.8 \pm 0.8$ & 0.988 \\
\hline \multicolumn{7}{|l|}{ Laboratory findings } \\
\hline Serum creatinine $(\mathrm{mg} / \mathrm{dL})$ & $0.9 \pm 0.3$ & $1.1 \pm 0.8$ & 0.660 & $0.9 \pm 0.2$ & $1.1 \pm 0.9$ & 0.571 \\
\hline eGFR (mL/min) & $76.4 \pm 25.2$ & $77.8 \pm 33.0$ & 0.912 & $80.0 \pm 25.6$ & $79.1 \pm 34.3$ & 0.951 \\
\hline Hemoglobin $(\mathrm{g} / \mathrm{dL})$ & $11.6 \pm 1.8$ & $12.8 \pm 1.8$ & 0.079 & $11.5 \pm 1.9$ & $12.7 \pm 1.8$ & 0.094 \\
\hline Platelet $\left(\times 10^{3} / \mu \mathrm{L}\right)$ & $225.7 \pm 33.8$ & $205.2 \pm 78.0$ & 0.490 & $231.3 \pm 33.2$ & $205.5 \pm 82.7$ & 0.448 \\
\hline \multicolumn{7}{|l|}{ Medication } \\
\hline Concomitant antiplatelet agents & $2(28.6)$ & $24(11.5)$ & 0.202 & $2(33.3)$ & $21(12.7)$ & 0.185 \\
\hline Heparin bridging therapy & $4(57.1)$ & $50(23.9)$ & 0.067 & $4(66.7)$ & $45(27.1)$ & 0.056 \\
\hline \multicolumn{7}{|l|}{ Anticoagulants } \\
\hline NOACs & $4(57.1)$ & $134(64.1)$ & 0.705 & $3(50.0)$ & $105(63.3)$ & 0.672 \\
\hline Warfarin & $3(42.9)$ & $75(35.9)$ & 0.705 & $3(50.0)$ & $61(36.7)$ & 0.672 \\
\hline High bleeding risk surgery & $6(85.7)$ & $163(78.0)$ & 1.000 & $6(100)$ & 163 (98.2) & 1.000 \\
\hline \multicolumn{7}{|l|}{ Discontinuation duration (day) } \\
\hline Before surgery & $4.4 \pm 2.1$ & $2.9 \pm 1.8$ & 0.028 & $4.7 \pm 2.3$ & $3.0 \pm 1.8$ & 0.029 \\
\hline After surgery & $1.8 \pm 4.4$ & $2.8 \pm 3.4$ & 0.539 & $1.8 \pm 0.4$ & $3.1 \pm 3.8$ & 0.444 \\
\hline Total & $5.7 \pm 2.6$ & $5.7 \pm 4.2$ & 0.978 & $6.2 \pm 2.5$ & $6.1 \pm 4.5$ & 0.985 \\
\hline
\end{tabular}

Values are presented as mean \pm standard deviation or number (\%).

TIA, transient ischemic attack; AP, anteroposterior; eGFR, estimated glomerular filtration rate; NOACs, non-vitamin K antagonist oral anticoagulants. 
Table 4. Clinical characteristics of patients with perioperative thromboembolism or major bleeding

\begin{tabular}{|c|c|c|c|c|c|c|c|c|c|c|}
\hline Patient & Sex & $\begin{array}{l}\text { Age } \\
\text { (yr) }\end{array}$ & Name of surgery & $\begin{array}{l}\mathrm{CHA}_{2} \mathrm{DS}_{2}- \\
\text { VASc score }\end{array}$ & $\begin{array}{l}\text { HAS-BLED } \\
\text { score }\end{array}$ & Anticoagulant & INR at event & $\begin{array}{l}\text { Discontinuation } \\
\text { duration (day) } \\
\text { (before/after) }\end{array}$ & $\begin{array}{l}\text { Heparin } \\
\text { bridging } \\
\text { therapy }\end{array}$ & Perioperative event \\
\hline 1 & Female & 74 & $\begin{array}{l}\text { Craniotomy/aneu- } \\
\text { rysm clipping }\end{array}$ & 5 & 4 & $\begin{array}{l}\text { Rivaroxaban } \\
20 \mathrm{mg}\end{array}$ & - & $9(7 / 2)$ & - & Stroke \\
\hline 2 & Female & 78 & Femur fracture $e^{a)}$ & 8 & 4 & Warfarin & 2.1 & $8(6 / 2)$ & + & Stroke \\
\hline 3 & Female & 75 & Total hysterectomy & 7 & 5 & Warfarin & 2.49 & $7(5 / 2)$ & + & Major bleeding \\
\hline 4 & Male & 75 & $\begin{array}{l}\text { Planned tooth } \\
\text { extraction }\end{array}$ & 4 & 2 & Apixaban $5 \mathrm{mg}$ & - & $3(3 / 0)$ & - & Systemic embolism \\
\hline 5 & Male & 76 & Femur fracture $\mathrm{e}^{\text {b) }}$ & 3 & 4 & Warfarin & 2.68 & $5(3 / 2)$ & + & Major bleeding \\
\hline 6 & Male & 63 & $\begin{array}{l}\text { Planned gastric } \\
\text { EMR }\end{array}$ & 3 & 2 & $\begin{array}{l}\text { Edoxaban } \\
60 \mathrm{mg}\end{array}$ & - & $6(6 / 0)$ & - & Stroke \\
\hline 7 & Male & 80 & Acetabular fracture ${ }^{c)}$ & 4 & 4 & $\begin{array}{l}\text { Rivaroxaban } \\
10 \mathrm{mg}\end{array}$ & - & $2(1 / 1)$ & + & Major bleeding \\
\hline
\end{tabular}

INR, international normalized ratio; EMR, endoscopic mucosal resection.

${ }^{a)}$ Closed reduction-internal fixation with proximal femur nail antirotation. ${ }^{b}$ Total hip replacement arthroplasty. ${ }^{\text {c) }}$ Open reduction-internal fixation with reconstruction plate.

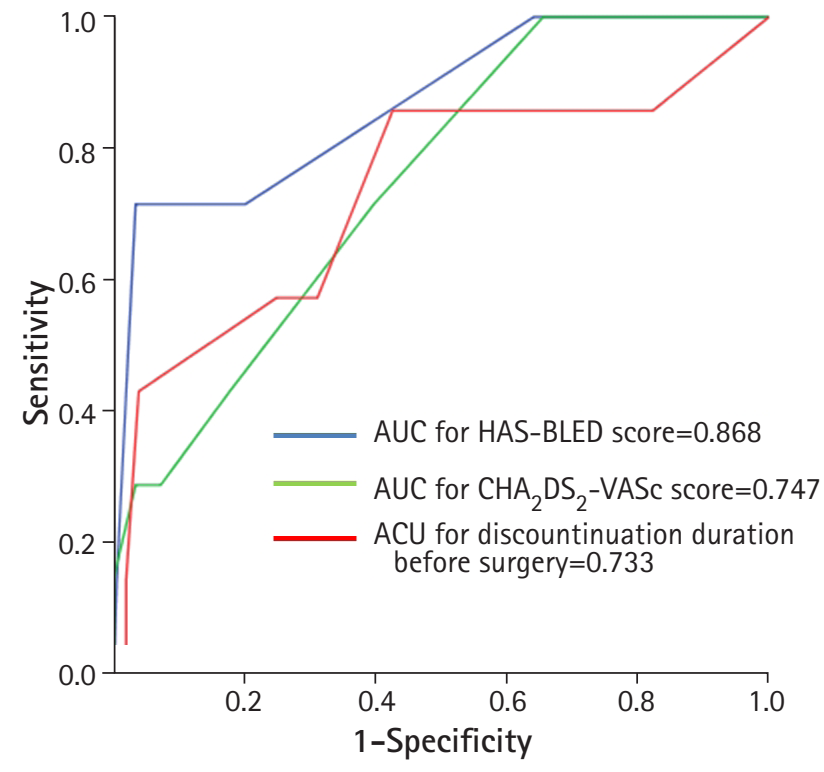

Fig. 2. Receiver operating characteristics curve analyses of the HAS-BLED and $\mathrm{CHA}_{2} \mathrm{DS}_{2}-\mathrm{VASc}$ scores and duration of preoperative anticoagulant discontinuation for predicting perioperative events. AUC, area under the curve.

sive bleeding or high bleeding risk, and therefore, it is challenging to clearly suggest the anticoagulant discontinuation duration after surgery. However, the recommended preoperative anticoagulant discontinuation duration on the basis of pharmacokinetic characteristics is relatively clear $[11,21-23,25]$; therefore, the minimum preoperative anticoagulant discontinuation duration that can prevent postoperative bleeding can reduce perioperative events. The results of our study are meaningful in supporting this point.

Heparin bridging therapy during the perioperative period is known to increase bleeding in patients taking NOACs or warfarin
$[26,27]$, which is consistent with our study results. However, the use of heparin bridging therapy did not significantly change the occurrence of any perioperative events including thromboembolism and major bleeding.

The $\mathrm{CHA}_{2} \mathrm{DS}_{2}$-VASc score is used to assess the thromboembolic risk in patients with NVAF. The higher the score, the higher the risk of thromboembolism; thus, anticoagulation is recommended. The HAS-BLED is a scoring system that was developed to assess the risk of major bleeding in patients taking anticoagulants; patients with a score $>3$ are considered to be a high-risk group for major bleeding and must exercise caution when taking anticoagulants. However, there has been no study on whether these scoring systems are useful for predicting stroke and major bleeding risks in patients with NVAF undergoing non-cardiac surgery. In the present study, we showed that a $\mathrm{CHA}_{2} \mathrm{DS}_{2}$-VASc score $>2.5$ and a HAS-BLED score $>3.5$ are associated with high perioperative events when anticoagulation therapy is discontinued for a certain hospitalization period. In addition, on analyzing these scoring systems along with the preoperative anticoagulant discontinuation duration, a significantly different perioperative event rate was observed between the high-risk (score, $3 ; 50.0 \%$ ) and the low-risk (score, $0-1 ; 0 \%$ ) groups. Therefore, perioperative management including an appropriate anticoagulant discontinuation strategy is more important in these high-risk groups.

This study has some limitations. First, this was a single-center, retrospective study. In addition, because we included patients treated since 2015, when NOACs began to be used to prevent stroke in patients with atrial fibrillation, a small number of patients were included. Second, our study included only those patients who had received consultation at the Department of Cardiology before undergoing surgery; therefore, patients who had discontinued antico- 


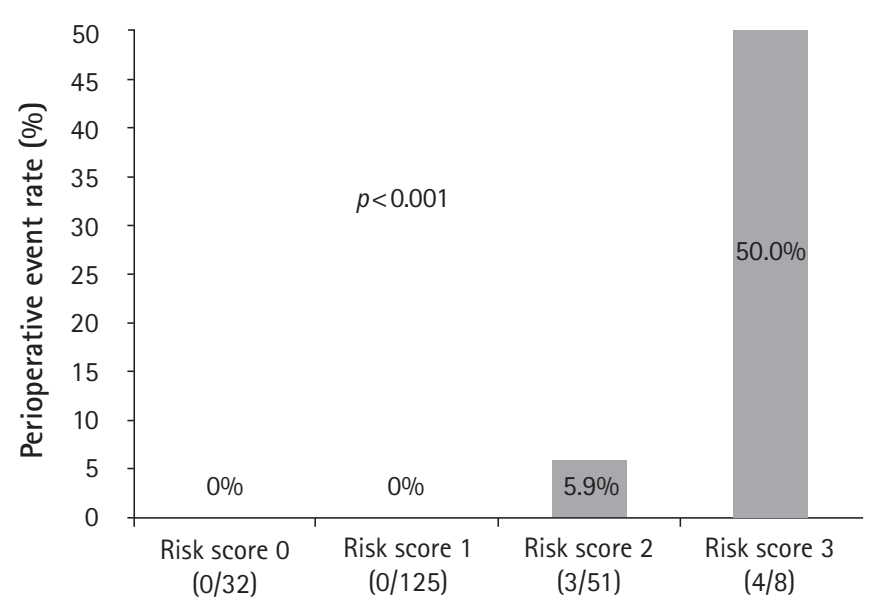

Fig. 3. Perioperative event rate categorized according to the cut-off levels of the HAS-BLED and $\mathrm{CHA}_{2} \mathrm{DS}_{2}$-VASc scores and duration of preoperative anticoagulant discontinuation. Significant differences in perioperative event rates are observed among the risk $0(0 \%), 1(0 \%), 2(5.9 \%)$, and $3(50.0 \%)$ groups $(p<0.001)$. HAS-BLED score $>3.5: 1, \mathrm{CHA}_{2} \mathrm{DS}_{2}-\mathrm{VAS} c>2.5: 1$, discontinuation duration before surgery $>2.5$ days: 1 .

Table 5. Multivariate logistic regression analysis for perioperative stroke/major bleeding

\begin{tabular}{lccc}
\hline Variable & Odds ratio & 95\% confidence interval & $p$-value \\
\hline CHA $_{2} \mathrm{DS}_{2}$-VASc score & 0.934 & $0.494-1.768$ & 0.835 \\
HAS-BLED score & 5.812 & $1.930-17.502$ & 0.002 \\
$\begin{array}{l}\text { Discontinuation duration } \\
\text { before surgery }\end{array}$ & 1.504 & $0.986-2.295$ & 0.058 \\
\hline
\end{tabular}

agulant use without consultation could have been missed. Third, it is challenging to determine whether the cause of major bleeding was the surgery itself or an early resumption of anticoagulant use. However, considering that all patients who experienced major bleeding resumed anticoagulant use within 2 days of surgery and that major bleeding occurred at least 4 days postoperatively, anticoagulant use most likely affected the major bleeding.

In conclusion, thromboembolic events and major bleeding are not uncommon during perioperative anticoagulant discontinuation in patients with NVAF. The high $\mathrm{CHA}_{2} \mathrm{DS}_{2}$-VASc and HASBLED scores and prolonged anticoagulant discontinuation duration are associated with perioperative events. Therefore, optimal strategies for interrupted anticoagulation are needed in patients with NVAF who are at a high risk of perioperative events.

\section{Acknowledgments}

\section{Conflicts of interest}

No potential conflict of interest relevant to this article was reported.

\section{Author contributions}

Conceptualization: MHB, BEP, SCC; Data curation: MHB, SYJ; Formal analysis: HJK, HNK, SYJ, YC; Methodology: MHB, BEP, YJP, HSP; Project administration: JHL; Visualization: BEP, DHY; Investigation: BEP; Resources: HJK, HNK; Software: SYJ; Supervision: YC; Writing-original draft: MHB, BEP; Writing-review \& editing: MHB, BEP, HJK, YJP, HSP, HNK, SYJ, YC, SCC, DHY, JHL.

\section{ORCID}

Bo Eun Park, https://orcid.org/0000-0002-5245-9863 Myung Hwan Bae, https://orcid.org/0000-0001-7677-4895 Hyeon Jeong Kim, https://orcid.org/0000-0002-3496-3142 Yoon Jung Park, https://orcid.org/0000-0001-5132-226X Hong Nyun Kim, https://orcid.org/0000-0002-9903-1848 Se Yong Jang, https://orcid.org/0000-0002-4981-879X Jang Hoon Lee, https://orcid.org/0000-0002-7101-0236 Dong Heon Yang, https://orcid.org/0000-0002-1646-6126 Hun Sik Park, https://orcid.org/0000-0001-7138-1494 Yongkeun Cho, https://orcid.org/0000-0001-9455-0190 Shung Chull Chae, https://orcid.org/0000-0002-9871-6976

\section{References}

1. Lip GY, Lim HS. Atrial fibrillation and stroke prevention. Lancet Neurol 2007;6:981-93.

2. Wolf PA, Mitchell JB, Baker CS, Kannel WB, D'Agostino RB. Impact of atrial fibrillation on mortality, stroke, and medical costs. Arch Intern Med 1998;158:229-34.

3. Hughes M, Lip GY; Guideline Development Group; National Clinical Guideline for Management of Atrial Fibrillation in Primary and Secondary Care; National Institute for Health and Clinical Excellence. Stroke and thromboembolism in atrial fibrillation: a systematic review of stroke risk factors, risk stratification schema and cost effectiveness data. Thromb Haemost 2008;99:295-304.

4. Go AS, Hylek EM, Phillips KA, Chang Y, Henault LE, Selby JV, et al. Prevalence of diagnosed atrial fibrillation in adults: national implications for rhythm management and stroke prevention: the AnTicoagulation and Risk Factors in Atrial Fibrillation (ATRIA) Study.JAMA 2001;285:2370-5.

5. Hylek EM, Go AS, Chang Y, Jensvold NG, Henault LE, Selby $\mathrm{JV}$, et al. Effect of intensity of oral anticoagulation on stroke severity and mortality in atrial fibrillation. $\mathrm{N}$ Engl J Med 2003;349:1019-26.

6. Rivera-Caravaca JM, Roldán V, Esteve-Pastor MA, Valdés M, Vicente V, Lip GY, et al. Cessation of oral anticoagulation is an 
important risk factor for stroke and mortality in atrial fibrillation patients. Thromb Haemost 2017;117:1448-54.

7. Heidbuchel H, Verhamme P, Alings M, Antz M, Diener HC, Hacke W, et al. Updated European Heart Rhythm Association practical guide on the use of non-vitamin-K antagonist anticoagulants in patients with non-valvular atrial fibrillation: executive summary. Eur Heart J 2017;38:2137-49.

8. Wysokinski WE, McBane RD, Daniels PR, Litin SC, Hodge DO, Dowling NF, et al. Periprocedural anticoagulation management of patients with nonvalvular atrial fibrillation. Mayo Clin Proc 2008;83:639-45.

9. Doherty JU, Gluckman TJ, Hucker WJ, Januzzi JL Jr, Ortel TL, Saxonhouse SJ, et al. 2017 ACC expert consensus decision pathway for periprocedural management of anticoagulation in patients with nonvalvular atrial fibrillation: a report of the American College of Cardiology Clinical Expert Consensus Document Task Force. J Am Coll Cardiol 2017;69:871-98.

10. Larsen TB, Skjøth F, Nielsen PB, Kjældgaard JN, Lip GY. Comparative effectiveness and safety of non-vitamin $\mathrm{K}$ antagonist oral anticoagulants and warfarin in patients with atrial fibrillation: propensity weighted nationwide cohort study. BMJ 2016; 353:i3189.

11. Steffel J, Verhamme P, Potpara TS, Albaladejo P, Antz M, Desteghe L, et al. The 2018 European Heart Rhythm Association Practical Guide on the use of non-vitamin K antagonist oral anticoagulants in patients with atrial fibrillation. Eur Heart J 2018;39:1330-93.

12. Ruff CT, Giugliano RP, Braunwald E, Hoffman EB, Deenadayalu N, Ezekowitz MD, et al. Comparison of the efficacy and safety of new oral anticoagulants with warfarin in patients with atrial fibrillation: a meta-analysis of randomised trials. Lancet 2014; 383:955-62.

13. Birman-Deych E, Radford MJ, Nilasena DS, Gage BF. Use and effectiveness of warfarin in Medicare beneficiaries with atrial fibrillation. Stroke 2006;37:1070-4.

14. Wallentin L, Yusuf S, Ezekowitz MD, Alings M, Flather M, Franzosi MG, et al. Efficacy and safety of dabigatran compared with warfarin at different levels of international normalised ratio control for stroke prevention in atrial fibrillation: an analysis of the RE-LY trial. Lancet 2010;376:975-83.

15. Lopes RD, Alexander JH, Al-Khatib SM, Ansell J, Diaz R, Easton JD, et al. Apixaban for reduction in stroke and other
ThromboemboLic events in atrial fibrillation (ARISTOTLE) trial: design and rationale. Am Heart J 2010;159:331-9.

16. Connolly SJ, Ezekowitz MD, Yusuf S, Reilly PA, Wallentin L; Randomized Evaluation of Long-Term Anticoagulation Therapy Investigators. Newly identified events in the RE-LY trial. N Engl J Med 2010;363:1875-6.

17. Giugliano RP, Ruff CT, Braunwald E, Murphy SA, Wiviott SD, Halperin JL, et al. Edoxaban versus warfarin in patients with atrial fibrillation. N Engl J Med 2013;369:2093-104.

18. Granger CB, Alexander JH, McMurray JJ, Lopes RD, Hylek EM, Hanna M, et al. Apixaban versus warfarin in patients with atrial fibrillation. N Engl J Med 2011;365:981-92.

19. Patel MR, Mahaffey KW, Garg J, Pan G, Singer DE, Hacke W, et al. Rivaroxaban versus warfarin in nonvalvular atrial fibrillation. N Engl J Med 2011;365:883-91.

20. Connolly SJ, Ezekowitz MD, Yusuf S, Eikelboom J, Oldgren J, Parekh A, et al. Dabigatran versus warfarin in patients with atrial fibrillation. N Engl J Med 2009;361:1139-51.

21. Levy JH. Discontinuation and management of direct-acting anticoagulants for emergency procedures. Am J Med 2016;129 (11 Suppl):S47-53.

22. Kornej J, Potpara T, Lip GY. Anticoagulation management in nonvalvular atrial fibrillation: current and future directions. Pol Arch Med Wewn 2013;123:623-34.

23. Kearon C, Hirsh J. Management of anticoagulation before and after elective surgery. N Engl J Med 1997;336:1506-11.

24. Garcia DA, Regan S, Henault LE, Upadhyay A, Baker J, Othman $\mathrm{M}$, et al. Risk of thromboembolism with short-term interruption of warfarin therapy. Arch Intern Med 2008;168:63-9.

25. Raval AN, Cigarroa JE, Chung MK, Diaz-Sandoval LJ, Diercks D, Piccini JP, et al. Management of patients on non-vitamin K antagonist oral anticoagulants in the acute care and periprocedural setting: a scientific statement from the American Heart Association. Circulation 2017;135:e604-33.

26. Douketis JD, Spyropoulos AC, Duncan J, Carrier M, Le Gal G, Tafur AJ, et al. Perioperative management of patients with atrial fibrillation receiving a direct oral anticoagulant. JAMA Intern Med 2019;179:1469-78.

27. Siegal D, Yudin J, Kaatz S, Douketis JD, Lim W, Spyropoulos AC. Periprocedural heparin bridging in patients receiving vitamin $\mathrm{K}$ antagonists: systematic review and meta-analysis of bleeding and thromboembolic rates. Circulation 2012;126:1630-9. 